Revista Brasileira de Agricultura Irrigada v.13, nº.5, p. 3627 - 3636, 2019

ISSN 1982-7679 (On-line)

Fortaleza, CE, INOVAGRI - http://www.inovagri.org.br

DOI: $10.7127 /$ rbai.v13n5001121

Protocolo 1121.19 - 25/03/2020 Aprovado em 30/03/2020

\title{
PRODUTIVIDADE DA BETERRABA FERTILIZADA COM DIFERENTES FONTES E DOSES DE BIOFERTILIZANTE
}

\author{
Jailson Antonio de Almeida Pereira ${ }^{1}$, Francisca Robevania Medeiros Borges ${ }^{2}$, Rafael Santiago da \\ Costa $^{3}$, Albanise Barbosa Marinho ${ }^{4}$, Sebastião Martinho Chiquete ${ }^{5}$
}

\begin{abstract}
RESUMO
Os produtores de hortaliças do Maciço de Baturité enfrentam problemas para condução de cultivos em relação à adubação, por baixa disponibilidade de nutrientes no solo. Diante disso, o presente trabalho avaliou os efeitos das fontes e doses de biofertilizantes, na produtividade da beterraba, no Maciço de Baturité, Ceará. O experimento foi conduzido na Fazenda Experimental Piroás, com delineamento experimental em blocos ao acaso, em parcela subdividida, com quatro blocos. As parcelas foram constituídas por duas fontes (esterco bovino e ovino) e as subparcelas por cinco doses de biofertilizante $\left(0,300,600,900\right.$ e $1.200 \mathrm{~mL} \mathrm{planta}^{-1}$ semana $\left.^{-1}\right)$. As variáveis analisadas foram massa fresca da parte aérea, massa seca da parte aérea, comprimento, diâmetro e massa da raiz tuberosa e produtividade. Houve interação significativa entre os tratamentos para massa fresca e seca da parte aérea e o diâmetro da raiz tuberosa, com superioridade para a fonte bovina. A fonte orgânica bovina também proporcionou maiores valores para a massa da raiz tuberosa e a produtividade. As doses do insumo influenciaram significativamente a produtividade, que foi estimada em $4.856,9 \mathrm{~kg}$ $\mathrm{ha}^{-1}$, para um stand de 102.040,8 plantas, na dose $992 \mathrm{~mL}$ planta $^{-1}$ semana $^{-1}$ de biofertilizante. Não houve influência significativa para o comprimento da raiz.
\end{abstract}

Palavras-Chave: adubação orgânica, beta vulgaris esculenta, produção.

\section{PRODUCTIVITY OF SUGAR BEET FERTILIZED WITH DIFFERENT SOURCES AND DOSES OF BIOFERTILIZER}

\footnotetext{
1 Engenheiro Agrônomo, Instituto de Desenvolvimento Rural (IDR), Universidade da Integração Internacional da Lusofonia Afro-Brasileira (UNILAB), Av. da Abolição, 3 - Centro, CEP: 62790-000, Redenção - CE, Brasil, jailpereira1@hotmail.com

2 Doutora, IDR, UNILAB, Av. da Abolição, 3 - Centro, CEP: 62790-000, Redenção - CE, Brasil, robevania@unilab.edu.br

${ }^{3}$ Doutorando em Fitotecnia/Agronomia, Departamento de Fitotecnia, Universidade Federal do Ceará (UFC), Fortaleza CE, Brasil, rafaelsantiagodacosta@yahoo.com.br

4 Doutora, IDR, UNILAB, Av. da Abolição, 3 - Centro, CEP: 62790-000, Redenção - CE, Brasil, albanise@unilab.edu.br

5 Mestrando em Agronomia, Universidade Estadual de Ponta Grossa, Ponta Grossa - PR, Brasil, sebastiaomartinho09@hotmail.com
} 


\section{ABSTRACT}

Vegetable producers in Maciço de Batata face problems in cultivating crops in relation to fertilization, with low availability of nutrients in the soil. In light of this, the present work analyzed the effects of sources and doses of biofertilizers, used in beet, in the Massif de Baturité, Ceará. The experiment was carried out at Fazenda Experimental Piroás, with an experimental design in randomized blocks, in a subdivided plot, with four blocks. As plots were constituted by two sources (bovine and sheep manure) and as subplots by five doses of biofertilizer (0, 300, 600, 900 and 1,200 $\mathrm{mL} \mathrm{plant}^{-1}$ week $\left.^{-1}\right)$. The variables analyzed were fresh mass of the aerial part, dry mass of the aerial part, length, diameter and mass of the tuberous root and reproduction. There was a significant interaction between the procedures for fresh and dry aerial part mass and tuberous root diameter, with superiority for a bovine source. A bovine organic source also provided higher values for tuberous root mass and rearing. As the doses used influence the use of the tool, estimated at 4,856.9 $\mathrm{kg} \mathrm{ha}^{-1}$, for a level of 102,040.8 plants, in the dose $992 \mathrm{~mL} \mathrm{plant}^{-1}$ week $^{-1}$ of biofertilizer. There was no significant influence on root length

Keywords: beta vulgaris esculenta, organic fertilization, production.

\section{INTRODUÇÃO}

O cultivo de beterraba (Beta vulgaris L.) é uma atividade agrícola viável para produtores que trabalham com agricultura familiar, pois a mesma apresenta alto valor econômico e vem sendo comercializada sob diferentes formas, tais como, in natura, processada e ainda como forrageira para o consumo animal (KLUGE; PRECZENHAK, 2016). É uma planta bianual pertencente à família Chenopodiacaea, originária das regiões de clima temperado da Europa e Norte da África, apresentando alto valor nutricional e que destaca entre as hortaliças pelo elevado conteúdo em vitaminas do complexo $\mathrm{B}$ e alguns minerais (LIMA JÚNIOR et al., 2011).

Albuquerque et al. (2015) afirmam que a beterraba é bastante exigente em termos nutricionais, requerendo um programa de adubação equilibrado capaz de repor os nutrientes extraídos pela cultura, afim de proporcionar melhor desenvolvimento e produtividade. Considerando que essa hortaliça apresenta ciclo curto, o sistema de cultivo, manejo da cultura, demanda por adubos, sejam orgânicos ou minerais, tornamse pontos importantes para o sucesso produtivo da cultura (SEDIYAMA et al., 2010).Sabe-se que a adubação é um fator determinante no processo produtivo, porém, essa prática representa um percentual significativo dos custos de produção (DOURADO NETO et al., 2012). Então, diante do aumento dos custos com insumos químicos, especialmente fertilizantes, e das problemáticas ambientais causadas pelo uso excessivo e indiscriminado dos mesmos, alternativas que visem melhorias na cadeia produtiva de uma forma mais sustentável, através da utilização de compostos orgânicos estão sendo estudadas (COSTA et al., 2017; GODOY, 2013).

Dentre essas alternativas, destaca-se a utilização de biofertilizante, um produto líquido obtido a partir da metabolização da matéria orgânica que pode ser aplicado ao solo para melhorar as características físicas, químicas e biológicas, auxiliando assim o desenvolvimento da cultura (BORGES FILHO; MACHADO, 2013). Nesse contexto, autores têm verificado respostas benéficas do biofertilizantes nas plantas, como exemplo de Souto et al. (2013) e Rebouças Neto et al. (2016), que constataram um incremento nas variáveis biométricas, na cultura do noni (Morinda citrifolia L.) e do milho (Zea mays L.), respectivamente.

Resultados positivos também foram observados por Chiconato et al. (2013) que, ao trabalhar com plantas de alface e doses de biofertilizante e adubação mineral, verificaram que a altura, o número de folhas, o diâmetro de copa e a massa de matéria fresca da parte 
aérea apresentam melhores resultados nos tratamentos com biofertilizante quando comparados a adubação mineral. Os mesmos autores, observaram ainda que a maior dose de biofertilizante $\left(60 \mathrm{~m}^{3} \mathrm{ha}^{-1}\right)$ apresentou os melhores resultados em todas as variáveis analisadas.

Diante disso, fica notório que o emprego deste insumo no cultivo de plantas pode melhorar a disponibilidade dos nutrientes, o aumento da produtividade e o cuidado com a saúde humana. Sendo assim, o objetivo deste trabalho foi avaliar os efeitos de doses de biofertilizante misto, a partir de fontes bovina e ovina, na produtividade e na pós-colheita da beterraba, nas condições edafoclimáticas da região do Maciço de Baturité, Ceará.

\section{MATERIAL E MÉTODOS}

$\mathrm{O}$ experimento foi conduzido em uma área da Fazenda Experimental Piróas (FEP) da Universidade da Integração Internacional da Lusofonia Afro-Brasileira (UNILAB), localizada no distrito de Barra Nova, município de Redenção, no Maciço de Baturité (04¹4'53"' S; 38 45'10” W; $240 \mathrm{~m}$ de altitude), durante o período de agosto a novembro de 2017.

Como o município não possui uma estação meteorológica, os dados de temperatura e umidade foram monitorados com um data logger de temperatura e umidade-sensor de luminosidade $\mathrm{HOBO}^{\circledR}$. Os dados de precipitação e evaporação foram mensurados com um pluviômetro e um Tanque Classe "A", respectivamente, ambos instalados próximos ao experimento.

A cultivar de beterraba utilizada foi a Early Wonder tal top, em vasos de $25 \mathrm{~L}$, preenchidos com uma camada de $5 \mathrm{~L}$ de brita número 1 no fundo e solo local mais areia, na proporção de 1:2. O solo foi classificado como areno-argisolo (EMBRAPA, 2013).

Ao longo da condução dos trabalhos experimentais, os tratos culturais realizados obedeceram às recomendações para a cultura da beterraba (TIVELLI et al., 2011), porém somente com os produtos recomendados para agricultura orgânica, como a aplicação quinzenal de extrato à base de castanha de caju e álcool para combate de algumas pragas, como por exemplo cochonilha e pulgão, assim como a remoção manual de plantas infestantes.

O delineamento experimental foi em blocos ao acaso no esquema de parcela subdivididas, com quatro blocos. As parcelas foram constituídas por duas fontes de esterco (bovino e ovino) e as subparcelas por cinco doses de biofertilizante $(0,300,600,900 \mathrm{e}$ $1.200 \mathrm{~mL}$ planta $^{-1}$ semana $\left.^{-1}\right)$, que foram parceladas e aplicadas duas vezes por semana, manualmente, de acordo com os tratamentos. Cada tratamento foi constituído de três plantas úteis, totalizando 120 unidades experimentais.

Os biofertilizantes mistos utilizados foram preparados a partir de $100 \mathrm{~L}$ de esterco bovino ou ovino (conforme tratamento), $30 \mathrm{~L}$ de esterco de galinha, $5 \mathrm{~L}$ de cinza de carvão e $270 \mathrm{~L}$ de água, conforme metodologia descrita em Viana et al. (2013).

O método de irrigação instalado foi do tipo localizado por gotejamento, dimensionado para operar com dois gotejadores por planta, com vazão média de $6 \mathrm{~L} \mathrm{~h}^{-1}$ (gotejadores de 2 e $4 \mathrm{~L} \mathrm{~h}^{-1}$ em cada vaso), sendo o controle das irrigações feito por registros instalados no início de cada linha.

O tempo de irrigação, com turno de rega diário, foi calculado a partir da evaporação medida no tanque classe "A", levando-se em consideração também, dentre outros, o coeficiente de cultivo $(\mathrm{Kc})$, a área do vaso (Av), o fator de cobertura e a eficiência de irrigação. Os valores de $\mathrm{Kc}$ seguiram recomendações de Folegatti (2008).

As variáveis analisadas foram massa fresca da parte aérea (MFPA), em g planta ${ }^{-1}$; massa seca da parte aérea (MSPA), em $\mathrm{g}$ planta $^{-1}$; diâmetro transversal da raiz $(\mathrm{mm})$; comprimento $(\mathrm{cm})$ e massa da raiz $(\mathrm{g})$ e, em posse dos dados, foi estimada a produtividade $\left(\mathrm{em} \mathrm{kg} \mathrm{ha}{ }^{-1}\right.$ ). Após a colheita, as plantas foram separadas em parte aérea e raiz. A parte aérea foi aferida para quantificação da MFPA. Após a aferição inicial, a parte aérea foi 
acondicionada em sacos de papel (kraft) identificados por tratamento e colocadas para secar em estufa com circulação de ar forçado, mantendo-se a temperatura na faixa de 65 a $70^{\circ} \mathrm{C}$. O tempo de secagem foi determinado por pesagens das amostras até manutenção de massa constante em balança analítica para aferição da MSPA.

$\mathrm{O}$ diâmetro e o comprimento da raiz tuberosa foram mensurados com um paquímetro digital. A massa fresca da raiz tuberosa foi quantificada em balança analítica. A produtividade média por hectare, para cada unidade experimental, foi estimada utilizando a massa fresca da raiz tuberosa e o stand de 102.040,82 plantas $\mathrm{ha}^{-1}$, conforme espaçamento adotado para o experimento. Os dados foram submetidos à análise de variância, pelo teste $\mathrm{F}$, com aplicação do teste de Tukey para comparação das médias e análise de regressão, conforme natureza dos tratamentos. $\mathrm{Na}$ análise de regressão, as equações que melhor se ajustaram aos dados foram escolhidas com base na significância dos coeficientes de regressão pelo teste $\mathrm{F}$ e no maior coeficiente de determinação $\left(\mathrm{R}^{2}\right)$. Em caso de interação significativa, procedeu-se o estudo de um fator dentro do outro (desdobramento dos dados).

\section{RESULTADOS E DISCUSSÃO}

A partir dos resultados observa-se que houve interação significativa para as variáveis MFPA, MSPA e diâmetro da raiz tuberosa (Tabela 1).

As fontes orgânicas e as doses de biofertilizante, com efeito isolado dos tratamentos, proporcionaram diferença estatística significativa para MFPA, MSPA, massa da raiz e produtividade.

As doses de biofertilizante foram significativas para a variável diâmetro da raiz. $\mathrm{O}$ comprimento da raiz não foi influenciado significativamente pelos tratamentos testados.

Tabela 1. Resumo das análises de variância da massa fresca da parte aérea (MFPA), massa seca da parte aérea (MSPA), comprimento da raiz (C. RAIZ), diâmetro da raiz (D. RAIZ), massa da raiz (M. RAIZ) e produtividade (PROD) em função das fontes orgânicas (bovina e ovina) e das doses de biofertilizante. Redenção - CE, 2018

\begin{tabular}{cccccccc}
\hline & & \multicolumn{5}{c}{ Quadrado Médio } \\
\cline { 3 - 7 } FV & GL & $\begin{array}{c}\text { MFPA } \\
\left(\mathrm{g} \mathrm{planta}^{-1}\right)\end{array}$ & $\begin{array}{c}\text { MSPA } \\
(\mathrm{g} \mathrm{planta} \\
1\end{array}$ & $\begin{array}{c}\text { C. } \\
\text { RAIZ } \\
(\mathrm{cm})\end{array}$ & $\begin{array}{c}\text { D. RAIZ } \\
(\mathrm{mm})\end{array}$ & $\begin{array}{c}\text { M. RAIZ } \\
(\mathrm{g})\end{array}$ & $\begin{array}{c}\text { PROD } \\
\left(\mathrm{kg} \mathrm{h}^{-1}\right)\end{array}$ \\
\hline Blocos & 3 & $63,224^{\mathrm{ns}}$ & $0,771^{\mathrm{ns}}$ & $35,79^{\mathrm{ns}}$ & $2,51^{*}$ & $46,11^{\mathrm{ns}}$ & $480094^{\mathrm{ns}}$ \\
Fontes (A) & 1 & $3521,856^{* *}$ & $4,306^{* *}$ & $60,03^{\mathrm{ns}}$ & $386,34^{\mathrm{ns}}$ & $2963,85^{*}$ & $30860569^{*}$ \\
Resíduo (A) & 3 & 42,275 & 0,995 & 39,74 & 48,71 & 246,72 & 2568887 \\
Doses (B) & 7 & $1753,978^{* *}$ & $20,032^{* *}$ & $50,81^{\mathrm{ns}}$ & $1320,67^{* *}$ & $2639,22^{* *}$ & $27480415^{* *}$ \\
Fonte x & 4 & $264,555^{*}$ & $3,581^{* *}$ & $13,59^{\mathrm{ns}}$ & $99,89^{*}$ & $453,84^{\mathrm{ns}}$ & $4725487^{\mathrm{ns}}$ \\
Doses & & 66,678 & 0,809 & 21,79 & 30,02 & 165,24 & 1720500 \\
Resíduo (B) & 4 & - & - & - & - & - \\
Total & 24 & - & 12,67 & 39,54 & 20,83 & 47,55 & 47,55 \\
\hline CV -A (\%) & - & 19,38 & 11,43 & 29,29 & 16,35 & 38,91 & 38,91 \\
CV -B (\%) & - & 24,34 & 119 &
\end{tabular}

**significativo a 1\%; *significativo a 5\% pelo teste $\mathrm{F}$; ns - não significativo pelo teste $\mathrm{F}$. FV-fonte de variação; GL grau de liberdade.

A aplicação do biofertilizante para a variável MFPA, independente da fonte, teve ajuste polinomial quadrático (Figura 1). A partir da análise de regressão verificou-se que a dose de $1.026 \mathrm{~mL}$ planta ${ }^{-1}$ semana $^{-1}$ do biofertilizante bovino misto proporcionou a maior MFPA de 63,39 $\mathrm{g} \mathrm{planta}^{-1}$. Para a fonte ovina, a análise indicou MFPA de 36,02 g planta $^{-1}$ com a aplicação da $1.167,5 \mathrm{~mL}^{-1}$ planta ${ }^{1}$ semana $^{-1}$. 


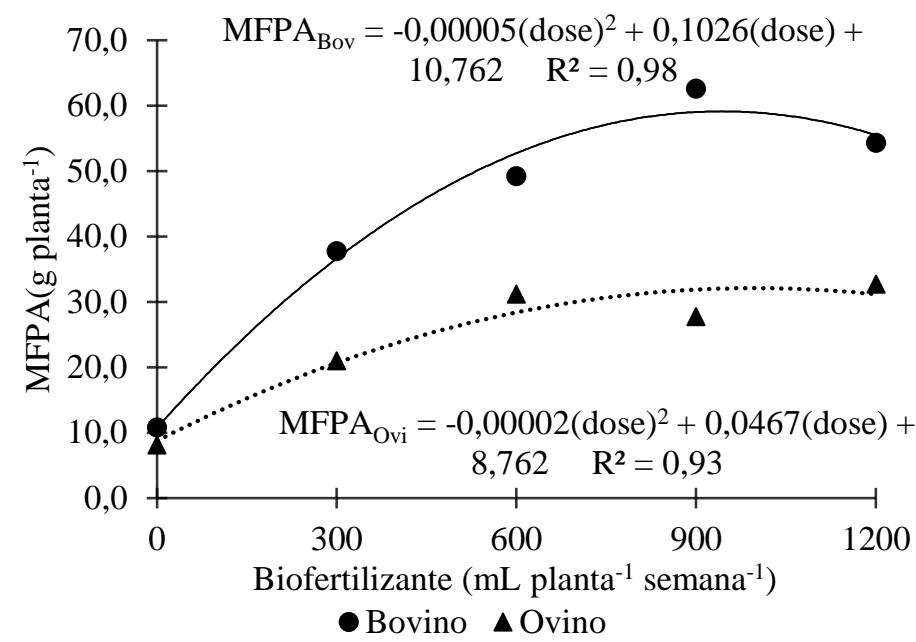

Figura 1. Massa fresca da parte aérea (MFPA) de beterraba em função das doses de biofertilizante misto e das fontes orgânicas. Redenção - CE, 2018

O biofertilizante bovino proporcionou uma maior massa fresca da parte aérea (MFPA) das plantas de beterraba em relação ao biofertilizante ovino, provavelmente por possuir, em sua composição nutricional, um maior teor de nutrientes quando comparado ao biofertilizante ovino. De forma semelhante, Peixoto Filho et al. (2013) avaliando a produtividade de alface com doses de esterco de frango, bovino e ovino em cultivos sucessivos, observaram em seu primeiro cultivo, que o esterco bovino, para massa fresca da planta, apresentou valores superiores aos dados obtidos com o esterco ovino.Para a massa seca da parte aérea (MSPA) houve uma interação entre fonte orgânica $\mathrm{x}$ doses de biofertilizante, com ajuste polinomial quadrático, para ambas as fontes orgânicas. A dose de $864,28 \mathrm{~mL}_{\text {planta }}{ }^{-1}$ semana $^{-1}$ de biofertilizante bovino indicou a maximização da massa seca para 10,67 $\mathrm{g} \mathrm{planta}^{-1}$.

A dose $833,33 \mathrm{~mL}$ planta $^{-1}$ semana $^{-1} \mathrm{de}$ biofertilizante ovino maximizou a massa seca da parte aérea para 7,25 g planta ${ }^{-1}$ (Figura 2).

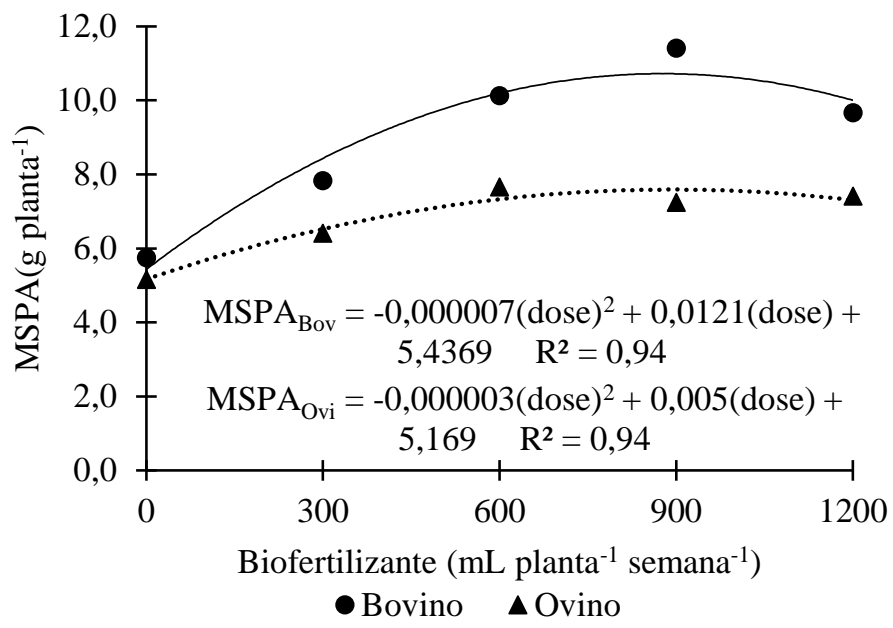

Figura 2. Massa seca da parte aérea (MSPA) de beterraba em função das doses de biofertilizante misto e das fontes orgânicas. Redenção - CE, 2018 
A parte aérea apresentou acúmulo de massa seca superior ao encontrado para a mesma cultivar em Grangeiro et al. (2007). Pesquisas realizadas por Chiconato et al. (2013), testando a aplicação de biofertilizante sob dois níveis de irrigação em plantas de alface, verificaram que a massa seca da parte aérea teve incremento com a dose máxima de biofertilizante, $\quad 60 \mathrm{~m}^{3} \quad \mathrm{ha}^{-1}$. Então, possivelmente, os resultados positivos quando as plantas foram adubadas com biofertilizante, especialmente o bovino, podem estar relacionados com o adequado fornecimento nutricional, o que favoreceu o acúmulo de biomassa da cultura.

A análise de regressão para diâmetro da raiz tuberosa indicou um ajuste polinomial quadrático (Figura 3).

Para a fonte bovina, o maior valor foi de $51,18 \mathrm{~mm}$ de diâmetro, proporcionado pela dose $870 \mathrm{~mL}$ planta ${ }^{-1}$ semana $^{-1}$ de biofertilizante. $\mathrm{Na}$ fonte ovina, o maior diâmetro foi de $41,08 \mathrm{~mm}$ na dose $990 \mathrm{~mL}$ planta $^{-1}$ semana $^{-1}$ de biofertilizante.

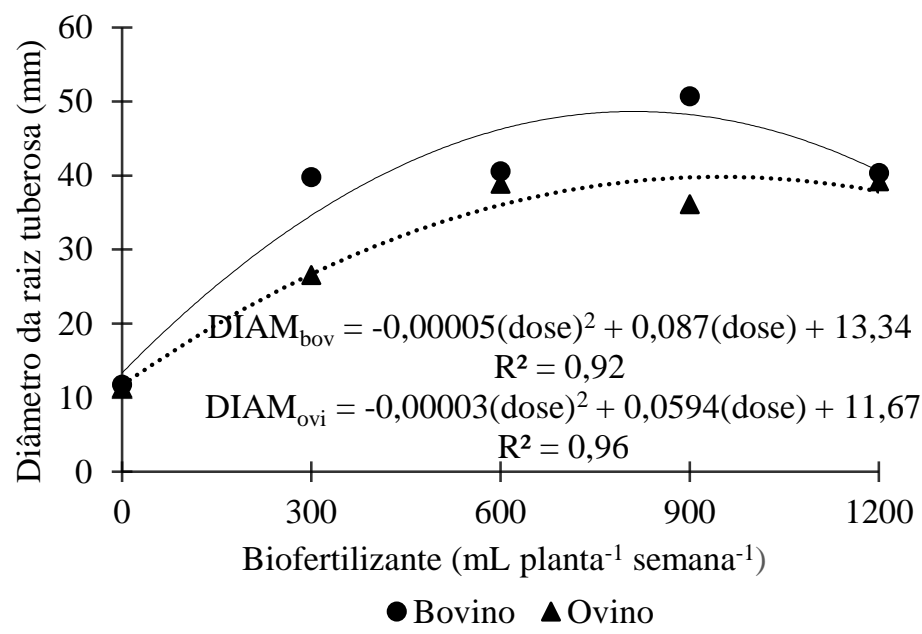

Figura 3. Diâmetro da raiz tuberosa da beterraba em função doses de biofertilizante misto e fontes orgânicas. Redenção - CE, 2018

Os resultados indicam uma superioridade da fonte bovina e uma possível explicação é a solubilidade do biofertilizante bovino em relação ao biofertilizante ovino. Assim, o biofertilizante bovino pode ter fornecido teores elevados de nitrogênio, fósforo, potássio, cálcio, magnésio e enxofre, importantes na nutrição das plantas.

Em complemento, vale ressaltar a importância da nutrição da planta, para o desempenho adequado dos aspectos fisiológicos e consequentemente produtivos. Nessa perspectiva, Sarmento et al. (2011), ao trabalharem com diferentes fontes de esterco e épocas de incorporação ao solo no cultivo da beterraba de mesa, observaram que as plantas que receberam a adubação orgânica com esterco bovino e caprino apresentaram taxas fotossintéticas superiores às das plantas que não receberam adubação. Segundo eles, isso ocorre possivelmente devido ao fato de o adubo orgânico proporcionar melhorias na fertilidade do solo.

No que diz respeito à massa da raiz, verificou-se que as plantas adubadas com a fonte bovina apresentaram uma superioridade de $41,4 \%$ em relação à fonte ovina (Figura 4A). Na produtividade, a fonte bovina também apresentou superioridade $41,4 \%$ em relação a fonte ovina (Figura 4B). Os maiores valores obtidos a partir da fonte bovina devem-se, ao fato que com a sua aplicação ao solo, este biofertilizante deve ter disponibilizado no momento adequado, os nutrientes necessários, atendendo, assim, as exigências nutricionais da cultura de beterraba. 

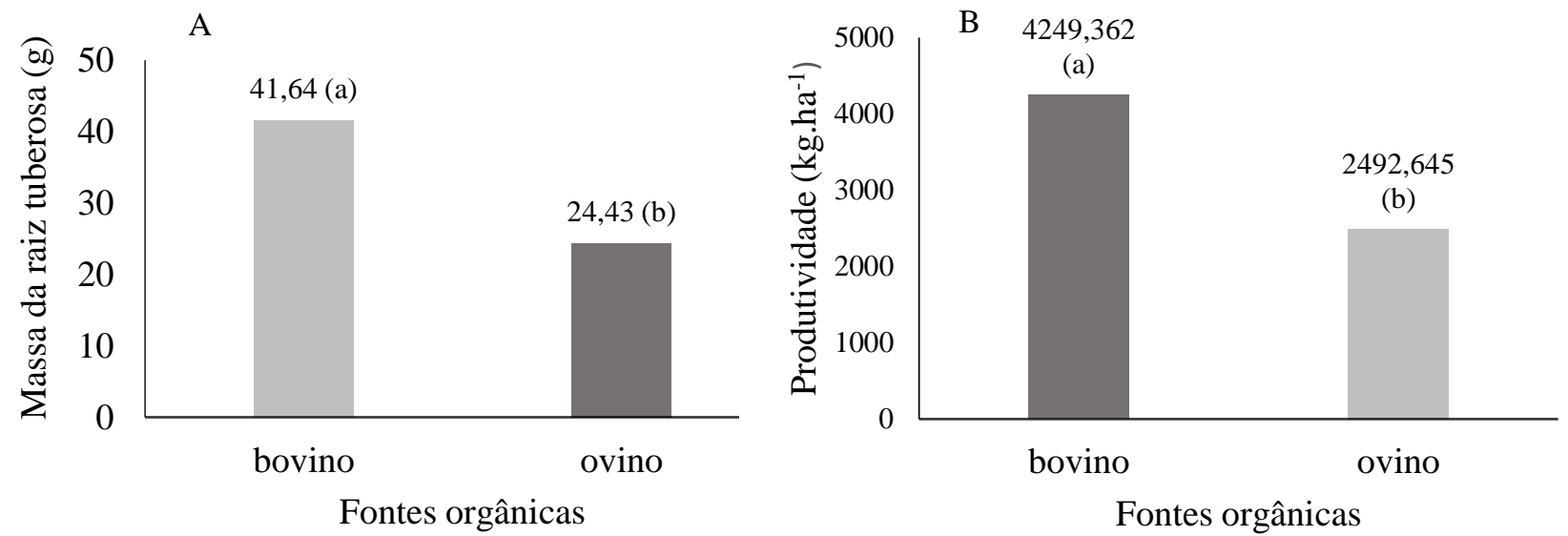

Figura 4. Massa da raiz tuberosa (A) e produtividade (B) da beterraba em função das fontes orgânicas de biofertilizante. Redenção - CE, 2018

Segundo Davari et al. (2012), o aumento das características produtivas em tratamentos com adubação orgânica e resíduos de culturas pode ser atribuído ao melhor desenvolvimento da planta devido à utilização eficiente dos nutrientes disponíveis no solo. $\mathrm{O}$ efeito positivo do biofertilizante, fonte de matéria orgânica, sobre a massa da raiz se deve, possivelmente, às melhorias proporcionadas às qualidades físicas, químicas e biológicas do solo, bem como à liberação lenta dos nutrientes de maneira a atender à necessidade nutricional da cultura por maior período.

Pela análise de regressão, os valores obtidos para a massa da raiz tuberosa se ajustaram ao modelo polinomial quadrático (Figura 5), em que a maior massa foi de 52,05 $\mathrm{g}$ na dose de $1.093,75 \mathrm{~mL}$ planta $^{-1}$ semana $^{-1}$. Fazendo uma comparação da massa máxima da raiz tuberosa-com a massa mínima $(3,79 \mathrm{~g})$, verificou-se um incremento de $91,8 \%$ das plantas adubadas em relação à dose zero.

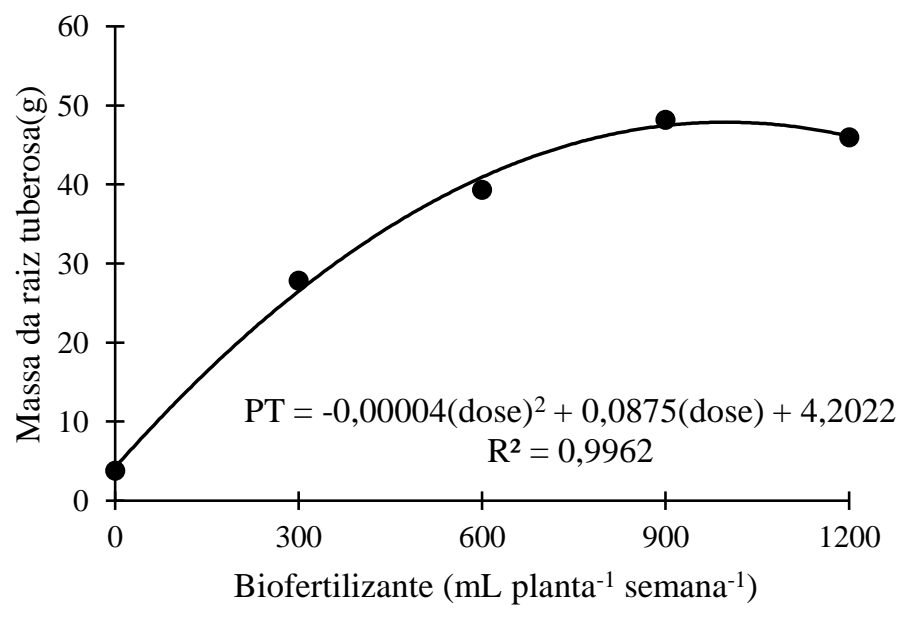

Figura 5. Massa da raiz tuberosa em função das doses de biofertilizante. Redenção - CE, 2018. 
Os dados da variável produtividade se ajustaram ao modelo polinomial quadrático, em que a produtividade $4.856,89 \mathrm{~kg} \mathrm{ha}^{-1}$, obtida para stand de 102.040,8 plantas, foi proporcionado pela dose de 991,977 $\mathrm{mL}$ planta $^{-1}$ semana $^{-1}$ (Figura 6). Ao comparar o ponto máximo com o ponto mínimo $(386,7 \mathrm{~kg}$ $\left.\mathrm{ha}^{-1}\right)$, verificou-se um incremento de $91,8 \%$ das plantas adubadas em relação à dose zero.

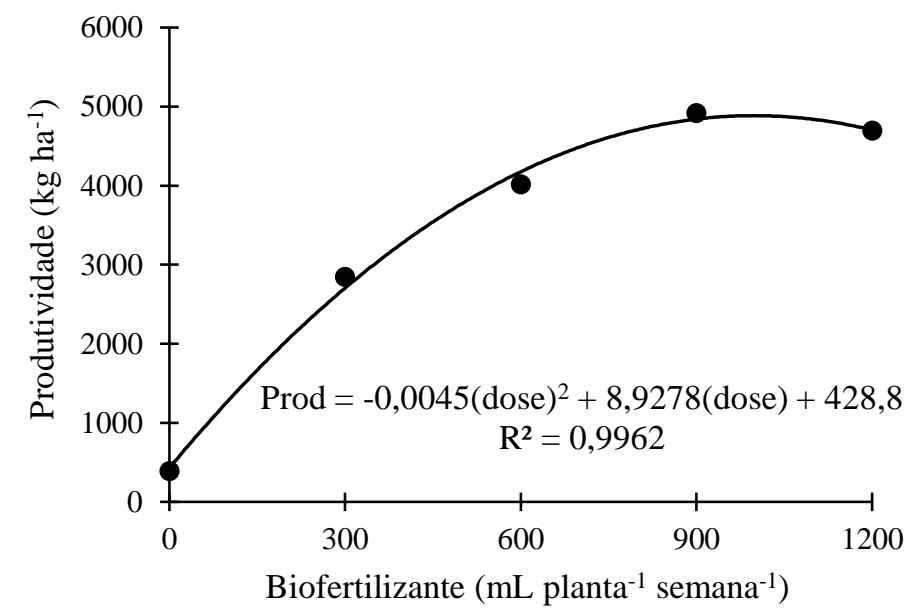

Figura 6. Produtividade da beterraba em função das doses de biofertilizante. Redenção - CE, 2018.

O biofertilizante proporcionou o aumento da massa da raiz provavelmente pela presença do nitrogênio, que contribui para o aumento da produtividade das culturas por promover a expansão foliar e o acúmulo de massa. Borchartt et al. (2011), em sua pesquisa com batata (Solanum tuberosum L.), constataram que o uso de esterco bovino foi eficiente, por proporcionar aumento na massa de tubérculos por planta, podendo ser uma alternativa de adubação.

Silva et al. (2012), trabalhando com adubação orgânica na cultura de inhame (Dioscorea cayennensis ham), concluíram que os resultados positivos da adição do esterco bovino sobre a produtividade de inhame se devem, além do fornecimento de nutrientes à sua ação na melhoria da capacidade de troca catiônica, promovendo maior disponibilidade de nutrientes para a planta, por um longo período.

Albuquerque et al. (2015) não identificaram diferenças significativas em diâmetro longitudinal, transversal e a espessura da raiz tuberosa, a massa fresca da raiz tuberosa, teor de umidade, teor de cinzas, sólidos solúveis e acidez titulável de beterraba submetida à adubação com biofertilizante fermentado. Marques et al. (2010) encontraram produtividade de $40 \mathrm{t} \mathrm{ha}^{-1}$ para um stand de 500.000 plantas, valores superiores aos encontrados neste trabalho. Lima Júnior (2011) obtiveram produtividade de 23,50 $\mathrm{t} \mathrm{ha}^{-1}$ na testemunha e no tratamento com a maior dose $\left(300 \quad \mathrm{~kg} \quad \mathrm{~K}_{2} \mathrm{O}\right) \quad$ a produtividade foi de $37,58 \mathrm{tha}^{-1}$.

\section{CONCLUSÕES}

A fonte bovina mostra superioridade nas características de produção em comparação à fonte ovina. As variáveis analisadas apresentam rendimento positivo com o biofertilizante, em que as doses mais indicadas são entre 900 e $1100 \mathrm{~mL}$ planta $^{-1}$ semana $^{-1}$.

\section{REFERÊNCIAS}

ALBUQUERQUE, J. R. T.; FORMIGA, A. S.; ROCHA, T. C.; COSTA, F. B.; BONDIM, A. R. O. Qualidade pós-colheita de beterraba submetida à adubação com biofertilizante fermentado. Revista Verde de Agroecologia e Desenvolvimento Sustentável, v. 10, n. 3, p. 41-46, 2015. https://doi.org/10.18378/rvads.v10i3.3652. 
BORCHARTT, L.; SILVA, I. de F.; SANTANA, E. O.; SOUZA, C.; FERREIRA, L. E. Adubação orgânica da batata com esterco bovino no município de Esperança-PB. Revista Ciência Agronômica, v. 42, n. 2, p. 482-487, 2011. http://dx.doi.org/10.1590/S180666902011000200030 .

BORGES FILHO, E. L.; MACHADO, E. C. Avaliação microbiana do solo e dos aspectos morfológicos de hortaliças após a adição de adubos orgânicos em hortas. e-Scientia, v. 6, n. 1, p. 8-15, 2013.

CHICONATO, D. A.; SIMONI, F.; GALBIATTI, J. A.; FRANCO, C. F.; CARAMELO, A. D. Resposta da alface à aplicação de biofertilizante sob dois níveis de irrigação. Bioscience Journal, v. 29, n. 2, p. 392-399, 2013.

COSTA, R. S.; OLIVEIRA, L. K. B.; HOLANDA, I. K. B.; COELHO, M. F. B.; AMORIM, A. V. Vegetative propagation of lemon balm on different substrates. Científica, v. 45, n. 4, p. 392-397, $2017 . \quad$ http://dx.doi.org/10.15361/19845529.2017v45n4p392-397.

DAVARI, M.; SHARMA, S. N.; MIRZAKHANI, M. Residual influence of organic materials, crop residues, and biofertilizers on performance of succeeding mung bean in an organic rice-based cropping system. International Journal of Recycling of Organic Waste in Agriculture, v. 1, n. 1, p. 1-14, 2012. https://doi.org/10.1186/22517715-1-14.

DOURADO NETO, D.; DARIO, G. J. A.; MARTIN, T. N.; SILVA, M. R.; PAVINATO, P. S.; HABITZREITER, T. L. Adubação mineral com cobalto e molibdênio na cultura da soja. Semina: Ciências Agrárias, v. 33, n. supl 1, p. 2741-2752, 2012. http://dx.doi.org/10.5433/1679-

0359.2012v33Sup11p2741.
EMBRAPA, Empresa Brasileira de Pesquisa Agropecuária. Sistema brasileiro de classificação de solos. 3 ed. Brasília-DF: Embrapa, 2013, 353p.

\section{FOLEGATTI, M. V. IRRIGAÇÃO - ENG} 115. Engenharia de Biossistemas (LEB), Escola Superior de Agricultura "Luiz de Queiroz" (ESALQ). 2008. Disponível em: http://www.esalq.usp.br/departamentos/leb/dis ciplinas/Folegatti/leb1571/Tabelas\%20comple tas.pdf Acesso em: 05 out. 2019.

GODOY, L. C. A logística na destinação do lodo de esgoto. Revista Científica on-lineTecnologia, Gestão e Humanismo, v. 2, n. 1, p. 1-5, 2013.

GRANGEIRO, L. C.; NEGREIROS, M. Z.; SOUZA, B. S.; AZEVEDO, P. E.; OLIVEIRA, S. L.; MEDEIROS, M. A. Acúmulo e exportação de nutrientes em beterraba. Ciência e Agrotecnologia, v. 31, n. 2, p. 267 - 273, 2007. http://dx.doi.org/10.1590/S141370542007000200001 .

KLUGE, R. A.; PRECZENHAK, A. P. Betalaínas em beterraba minimamente processada: perdas e formas de preservação. Revista Iberoamericana de Tecnología Postcosecha, v. 17, n. 2, p. 175-192, 2016.

LIMA JÚNIOR, S.; FACTOR, T. L.; SILVEIRA, J. M. C.; PURQUERIO, L. F. V.; CALORI, A. H.; GUIMARÃES, R. S.; SANTELLO, M. C.; RONCHI, R. S. M. Produtividade de beterraba cultivada em plantio direto em função de doses e parcelamento da adubação potássica. Horticultura Brasileira, v. 29, n. 2, p. 39583965, 2011.

MARQUES, L. F.; MEDEIROS, D. C.; COUTINHO, O. L.; MARQUES, L. F.; MEDEIROS, C; C.; VALE, L. S. Produção e qualidade da beterraba em função da adubação com esterco bovino. Revista Brasileira de Agroecologia, v. 5, n. 1, p. 24-31, 2010. 
PEIXOTO FILHO, U. J.; FREIRE, M. B. G. S.; FREIRE, F. J.; MIRANDA, M. F. A.; PESSOA, L. G. M.; KAMIMURA, K. M. Produtividade de alface com doses de esterco de frango, bovino e ovino em cultivos sucessivos. Revista Brasileira de Engenharia Agrícola e Ambiental, v.17, n.4, p.419-424, 2013.

REBOUÇAS NETO, M. O.; CAMPOS, J. R.; VERAS, C. L.; SOUSA, I. R.; MONTEIRO FILHO, L. R. Crescimento inicial do milho sob diferentes concentrações de biofertilizante bovino. Cadernos Cajuína, v. 1, n. 3, p. 4-14, 2016.

SARMENTO, A. L. R.; PEREIRA, F. H. F.; SILVA, M. C.; MEDEIROS, J. E.; FREIRE, E. C. B. S. Fontes e tempo de incorporação de nutrientes no cultivo da beterraba. Revista Verde de Agroecologia e Desenvolvimento Sustentável, v. 6, n. 2, p.50-58, 2011.

SEDIYAMA, M. A. N.; SANTOS, M. R.; VIDIGAL, S. M.; SANTOS, I. C.; SALGADO, L. T. Ocorrência de plantas daninhas no cultivo de beterraba com cobertura morta e adubação orgânica. Planta daninha, v. 28, n. 4, p. 717-725, 2010. http://dx.doi.org/10.1590/S0100-

83582010000400003.

SILVA, J. A.; OLIVEIRA, A. P.; ALVES, G. S.; CAVALCANTE, L. F.; OLIVEIRA, A. N. P.; ARAUJO, M. A. M. Rendimento do inhame adubado com esterco bovino e biofertilizante no solo e na folha. Revista Brasileira de Engenharia Agrícola e Ambiental, v. 16, n. 3, p. 253-257, 2012. http://dx.doi.org/10.1590/S141543662012000300003.

SOUTO, A. G. L.; CAVALCANTE, L. F.; NASCIMENTO, J. A. M.; MESQUITA, F. O.; LIMA NETO, A. J. Comportamento do noni à salinidade da água de irrigação em solo com biofertilizante bovino. Irriga, v. 18, n. 3, p. 442-453, 2013. https://doi.org/10.15809/irriga.2013v18n3p44 2.

TIVELLI, S. W.; FACTOR, T. L.; TERAMOTO, J. R. S.; FABRI, E. G.; MORAES, A. R. A. de; TRANI, P E.; MAY, A. Beterraba: do plantio à comercialização. Campinas: Instituto Agronômico, 2011. 45p. (Série Tecnologia APTA. Boletim Técnico IAC, 210). Disponível em: http://www.iac.sp.gov.br/publicacoes/publicac oes_online/pdf/bt_210.pdf. Acesso em: 05 out. 2019.

VIANA, T. V. A.; SANTOS, A. P. G.; SOUSA, G. G.; PINHEIRO NETO, L. G.; AZEVEDO, B. M.; AQUINO, B. F. Trocas gasosas e teores foliares de NPK em meloeiro adubado com biofertilizantes. Revista Brasileira de Ciências Agrárias, v. 8, n. 4, p. 595-

601,2013.DOI:10.5039/agraria.v8i4a3260. 